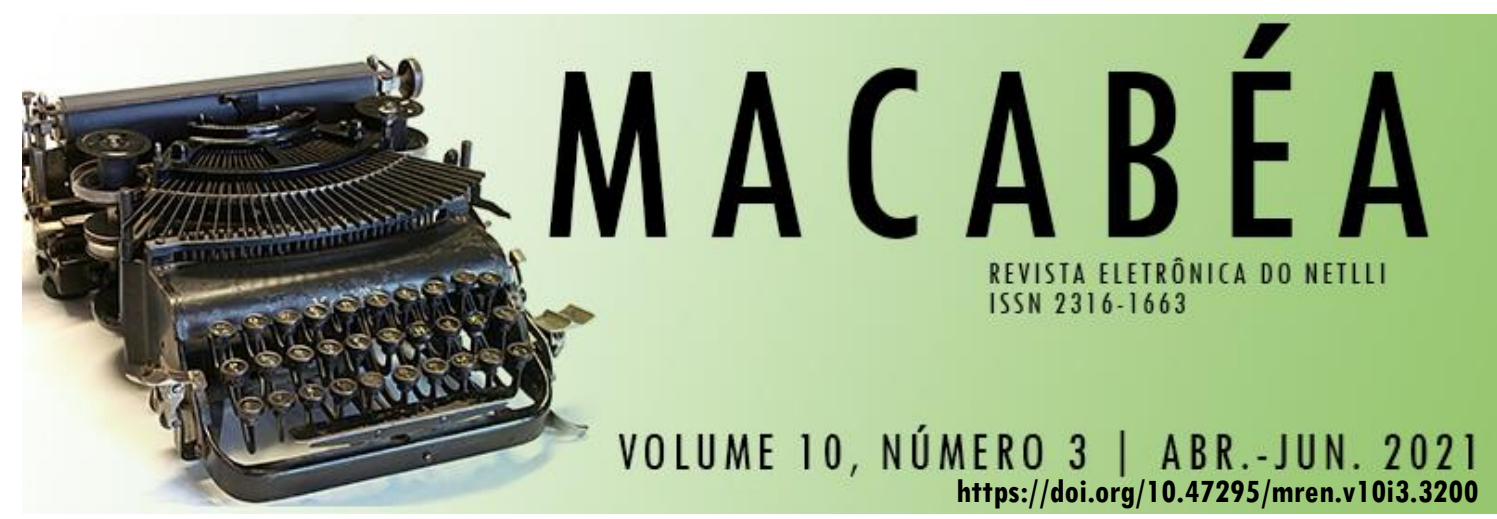

\title{
DA VIDÊNCIA NARRATIVA NOS ESCRITOS DE CAIO FERNANDO ABREU
}

\section{ABOUT THE VISIONARIES IN CAIO FERNANDO ABREU'S WRITINGS}

GABRIELLE FORSTER

\author{
RESUMO | INDEXAÇÃO | TEXTO | REFERÊNCIAS | CITAR ESTE ARTIGO | A AUTORA \\ RECEBIDO EM 13/02/2021 • APROVADO EM 24/03/2021
}

\begin{abstract}
The search for the establishment of more meaningful exchanges and bonds with the other is a constant in Caio Fernando Abreu's work and, although this desire is rarely realized, the incessant search and movement towards the other opens perspectives that expand the field of the sensitive, indicating powers of affection that ask for passage. From this, we seek to trace the presence of visionaries in the writer's tales, considering, for that, the mobility of the narrative focus. With the breadth of observation coupled with an elastic, fragmented and plural point of view, it is shown that the views conveyed violate the communicative purpose to thus compose ways of access to an affective transformation yet to come.
\end{abstract}

\section{Resumo}

A busca pelo estabelecimento de trocas e vínculos mais significativos com 0 outro é uma constante na obra de Caio Fernando Abreu. Embora raramente esse desejo se concretize, a procura incessante e o movimento em direção ao outro abrem perspectivas que ampliam o campo do sensível, indicando potências de afeto que pedem passagem. A partir desse reconhecimento, busca-se traçar a presença de visionários em contos do escritor, considerando, para tanto, a mobilidade do foco narrativo. Com a amplitude de observação acoplada a um ponto de vista elástico, fragmentado e plural, demonstra-se que as visões veiculadas transgridem 0 propósito comunicativo para, assim, compor vias de acesso a uma transformação afetiva ainda por vir. 


\section{Entradas para indexação}

KEYWORDS: Short stories. Caio Fernando Abreu. Visionaries

PALAVRAS-CHAVE: Contos. Caio Fernando Abreu. Visionários.

\section{Texto integral}

Adentrar o universo literário de Caio Fernando Abreu é como percorrer um caminho que te leva continuamente ao outro. Ausente, amante, amigo, ouvinte, fugidio ou por chegar, ele sempre está lá, como um prenúncio das infinitas potências possíveis que se originam de um encontro. A essa possibilidade se abrem seus personagens, sob a forma de uma procura incessante, escavada no percurso das palavras, de uma espera como acontecimento que se realiza no vislumbre desse encontro. Enquanto esperam alguém que não chega, um telefone que não toca, um toque que não acontece ou que é apenas superficial, criam essa possibilidade como visão de outras formas de encontro, experiência e existência.

"Um ser humano jamais atravessa incólume o círculo magnético de outro" (ABREU, 2005a, p. 89). Por isso, mesmo que o encontro não aconteça e a comunicação falhe, há aspectos que fulguram por trás desse desentendimento, indicando a necessidade de uma mutação afetiva ainda por vir. Ao mesmo tempo que o desejo de estabelecer vínculos mais profundos e duradouros encontra como obstáculo o individualismo exacerbado e a superficialidade das trocas interhumanas contemporâneas, esse mesmo desejo se expande na esfera dessa procura insistente pelo outro e por novas formas de relação consigo mesmo e com o mundo, forçando os personagens a expandirem-se na direção da ampliação do campo do sensível. Relacionados à essa percepção devem ser compreendidos os narradores que se afirmam como visionários em contos de Caio Fernando Abreu: é a eles e à sua constituição narrativa que daremos atenção nesse artigo.

Tomados por visões que fogem do comum compartilhado, esses narradores não podem compactuar com as premissas mecânicas e rotineiras a partir das quais observam a vida se desenvolver, residindo nisso o tamanho desassossego que expressam. Sem poder evitar a amplitude de compreensão, o que aparece na perspectiva alheia como parte natural e incontornável de suas existências, lhes soa como algo intolerável que os impulsiona a movimentar-se em busca de novas dimensões existenciais. Agitados por estados inéditos de percepção, são lançados em um processo de desestabilização que desfaz os contornos de suas figuras e o composto de relações plausíveis, obrigando-os, através da instabilidade produzida, a perscrutar outras formas de vivência e de convivência, já que as encontradas na ordem do dia se mostram incapazes de dar conta dos fluxos de transformação que exigem passagem. Nesse sentido, esses narradores podem ser vistos como videntes; aqueles que de acordo com a acepção deleuzo-guattariana,

têm uma luneta refinada e complexa. Mas certamente não são chefes. E veem uma coisa totalmente diferente do que os outros. Veem toda uma micro-segmentaridade, detalhes de detalhes, "tobogã de possibilidades", minúsculos movimentos que não 
esperam para chegar às bordas, linhas ou vibrações que se esboçam bem antes dos contornos [...] Todo um rizoma, uma segmentaridade molecular que não se deixa sobrecodificar por um significante como máquina de recortar, nem mesmo atribuir a uma determinada figura, determinado conjunto ou determinado elemento (DELEUZE; GUATTARI, 1996, p. 74).

Ao contrário dos outros, mais sobreviventes que viventes, que giram de acordo com a roda, acomodados, sem questionar as situações, esses observadores, também denominados pelos referidos filósofos como visionários ou vigilantes telescópios, vibram em outro ritmo, exigindo da vida mais do que a composição atual pode lhes dar. Não ocupam postos importantes porque sua diferença reside justamente na insubordinação ao consenso, na adoção de um prisma que não se deixa capturar e que movido pelo desentendimento vê no mundo possibilidades ainda não configuradas. 0 que percebem, a partir do estado de crise e de perda no qual a perspectiva ampla os coloca, são modificações que as próprias relações de forças postas em prática sugerem, mas que por estarem ativadas em um âmbito molecular, não podem ser detectadas a olho nu, mas sentidas e vislumbradas em outras esferas de percepção.

Por isso, a capacidade de vidência aqui mencionada não se refere à aptidão paranormal, à qual o significado corrente do termo aponta, mas indica a inclinação para observar microvazamentos que começam a se delinear conforme as coordenadas de determinado sistema são estremecidas por linhas que escapam à sobrecodificação, pois o vidente, conforme explica Fraçois Zourabichvili,

não é aquele que antevê o futuro; ao contrário, ele não vê ou não prevê, para si, nenhum futuro. 0 vidente apreende o intolerável em uma situação; ele tem visões, entendamos, aí, percepções em devir ou perceptos, que colocam em xeque as condições usuais da percepção, e que envolvem uma mutação afetiva. A abertura de um novo campo de possíveis está ligada a estas novas condições de percepção: o exprimível de uma situação irrompe, bruscamente (ZOURABICHVILI, 2000, p. 340).

Nesse sentido, o ângulo a partir do qual observam as situações é subversivo em relação a uma forma de pensar arborescente que classifica e divide tudo em partes bem delimitadas, pois o que veem vai além das aparências e dos códigos. Dessa forma, "eles são capazes de detectar no abismo as microinfrações mais leves, que os outros não veem; mas constatam também os terríveis danos da Luneta de recortar, sob sua aparente justiça geométrica" (DELEUZE; GUATTARI, 1996, p. 7576). Por conseguinte, ao mesmo tempo que eles reconhecem as problemáticas que os limites impostos produzem, também observam possibilidades de resistência naquilo que embora demarcado, começa a mover-se na direção de novas dobras do sensível, nas quais concepções podem ser desestabilizadas, rostificações desfeitas e moldes de instituições tradicionais reformulados. Entretanto, tais transformações 
não são fatos realizados, mas realizáveis; são potenciais abertos que o visionário percebe através do mal-estar que determinadas configurações provocam, exigindo que se repense categorias do senso-comum para engendrar composições sociais diferentes, já que "o vidente vê o possível e, com isso ascende a uma nova possibilidade de vida que pede para se realizar" (ZOURABICHVILI, 2000, p. 341).

Ao manifestar uma maneira de olhar o mundo que se aproxima da noção de olho vibrátil, proposta por Suely Rolnik, ou seja, "o do respiradouro para o invisível" (ROLNIK, 2011, p. 32), aquele que capta "uma certa inquietação, como se algo estivesse fora do lugar ou de foco" (ROLNIK, 1997, p. 1), os visionários "sentem nitidamente que veem algo diferente dos outros" (DELEUZE; GUATTARI, 1996, p. 76). Sensíveis aos movimentos imprevistos que toma a vida, aos diversos fluxos que a arrastam na direção de um novo composto, notam que destoam dos demais ao perceber modificações não detectadas concretamente e opostas à lógica que equivale real a efetuado. Por isso, nos escritos de Caio F., onde a presença de narradores/videntes se faz visível, tal amplitude de visão, quando mencionada, aparece como uma marca ou um dom estranho, que lhes difere dos outros, conforme podemos observar na citação a seguir, retirada do conto Eles, da coletânea $\mathbf{O}$ ovo apunhalado:

os que trazem a marca, mesmo que não saibam dela, esses olham as coisas com olhar de sangue. Os que sabem da marca ganham uma luz estranha e uma lentidão e um jeito de quem sabe todas as coisas. Os outros todos olham todas as coisas com um olhar torvo. Os outros são escuros, estúpidos, pobres. Os outros não sabem (ABREU, 2001, p. 64).

No entanto, embora tal visão, que aparece sob a forma de uma incógnita, de uma procura, de uma sensação vislumbrada, os torne distintos dos demais, a força desta não deve ser buscada no afastamento, mas no movimento em direção ao outro que a torna possível, ainda que enquanto diferença, pois o que essa percepção inédita veicula se refere menos a "[...] uma tomada de consciência do que a eclosão de uma nova sensibilidade [...]" (ZOURABICHVILI, 2000, p. 340), que o vidente entrevê como possibilidade de engendrar novas relações que pedem passagem em determinado campo social. Por isso, nos contos de Caio Fernando Abreu, a abertura ao outro é fundamental para potencializar visões, que indicam a necessidade de engendrar mudanças afetivas a partir do mal-estar que determinadas configurações produzem.

Nesse sentido, em seus escritos, a capacidade de vidência dos narradores se mostra intimamente entrelaçada com a mobilidade de seu foco. Tanto em primeira quanto em terceira pessoa, aquele que narra se apresenta vulnerável ao outro, sendo dessa abertura que surge sua visão. Seja este o protagonista, ou aquele que observa os personagens e com eles compartilha a nova percepção, sua perspectiva nunca é estável e totalizante; ao contrário, ela emerge de uma zona de contágio com o alheio, se vê lançada em um movimento de devir-outro, que impede a permanência do mesmo. 
Conforme sugere Bruno de Souza Leal, na literatura de Caio F., "[...] mesmo quando em primeira pessoa a narrativa apresenta um distanciamento autocrítico, auto-irônico. Apesar de próximo, o narrador preserva um espaço entre si e o que ele apresenta [...]" (LEAL, 2002, p. 54). Portanto, quando o narrador é também o protagonista, ele não se apresenta fechado e estático, mas em contínua mudança; acossado por estados inusitados que invadem seu perfil, desarticulando-o e empurrando-o a buscar novas configurações que deem conta dos fluxos de desejo que começam a circular, modificando sua paisagem existencial. Logo, em uma mesma voz é possível reconhecer dois ângulos de observação: aquele oriundo da figura atual e o outro, que descobre nessa forma algo que já não funciona.

No conto Itinerário, isso pode ser notado com facilidade, já que o conflito se desenvolve em torno da tensão entre duas perspectivas: incongruentes, mas oriundas de um mesmo sujeito, que, fragmentado, teme os descaminhos de si mesmo. Sozinho em um parque, o narrador-personagem é tomado por uma sensação nova a transmitir-lhe uma percepção fluídica e informe de sua figura: “[...] minhas paredes se dissolvem. Não as vejo mais, e por um instante meu pensamento se expande, rompendo limites num percurso desenfreado" (ABREU, 2005a, p. 61). Além disso, conforme seu perfil começa a tornar-se difuso, a relação com o ambiente ao redor também se modifica, pois a apreensão objetiva do mundo cede lugar a uma zona de contágio própria do devir: "Nesse rápido espraiar, meu ser anexa a si as coisas externas. 0 parque, as árvores, o sol, as gentes [...] se aninham em mim, fazendo parte do meu ser" (ABREU, 2005a, p. 61).

No entanto, o protagonista teme essa visão, justamente pelo fato de que ela lhe cobre de incertezas e lhe obriga a repensar e reformular suas premissas, nas quais se agarra com segurança, conforme confessa: "No vácuo de mim eu me despenco. Porque seria preciso também abdicar de mim mesmo para novamente reconstruir-me [...] já escolhi as porções que me são convenientes, esquecendo deliberado as outras" (ABREU, 2005a, p.63). Então, luta constantemente ao longo de todo o texto para voltar a se enquadrar novamente na imagem que compôs de si, para assumir a máscara com a qual se apresenta aos outros, desejando que vejam o quanto é "[...] normal trivial banal e até vulgar dentro deste terno escuro, antiquado" (ABREU, 2005a, p. 61).

Como a sensação pela qual é tomado lhe parece uma ofensa à comunicação espetacular, que se compraz em dividir e catalogar, quase grita: "não sou um assassino: sou um homem no parque!” (ABREU, 2005a, p. 61), negando, por fim, os fluxos cambiantes de sua subjetividade, as outras porções de si "[...] que agora se movimentam revoltadas, pedindo passagem em gritos mudos, na ânsia de transcender limites, violentar fronteiras, arrebentando para a manhã de sol" (ABREU, 2005a, p. 63). Porém, ironizando também a sua própria opção, deixando que ela pareça absurda e artificial, e criando assim uma lacuna entre aquilo que ele afirma e a ideia implícita e desestabilizadora transmitida acerca de sua opinião (consensual).

Desse modo, o referido recurso estético funciona tanto para acentuar a ambiguidade do narrador-personagem, oscilante ao longo de todo o conto entre duas possibilidades de si mesmo, quanto para criar um espaço de resistência. Se, ainda que indeciso e fragmentado, o personagem decide de maneira explícita retornar à sua rotina e à concepção estereotipada de si mesmo, a ironia que envolve 
sua fala se distancia da opção verbalizada, sugerindo um possível retorno de suas incertezas, na mesma medida em que convida o leitor a não repetir o desejo já objetificado do protagonista. É com essa reabertura à escolha, extensiva ao âmbito da recepção, que o conto "termina" com justeza do advérbio "eis" (ABREU, 2005a, p.65), lembrando-nos o velho dilema de Hamlet que soa agora aqui, muito próximo.

Essa visão inacabada da subjetividade, anunciada e relutante em Itinerário, e que significa menos estar incompleto que por completar-se, é uma constante na obra de Caio Fernando Abreu, e para configurá-la as estratégias de focalização são fundamentais. Em alguns de seus contos, o outro deixa de ser apenas parte potencial de si mesmo para transformar-se em uma presença localizável fora do espaço introspectivo, cuja relação também ilumina a fragmentação do sujeito, porém torna mais visível que a "[...] vulnerabilidade é condição para que o outro deixe de ser simplesmente objeto de projeção de imagens pré-estabelecidas e possa se tornar uma presença viva, com a qual construímos nossos territórios de existência e os contornos cambiantes de nossa subjetividade [...]" (ROLNIK, 2006, p. 2).

Para isso, ou seja, no sentido de iluminar "[...] que um ser humano jamais atravessa incólume o círculo magnético de outro [...]" (ABREU, 2005a, p. 89), conforme alerta um dos narradores caiofernandianos, o escritor gaúcho se vale de recursos estéticos diferentes. Enquanto no conto Os sobreviventes, não há uma única perspectiva narrativa, mas dois pontos de vista que se interpenetram constantemente sem aviso prévio, configurando um discurso híbrido, cujo sentido reside no entrecruzamento das vozes; em $A$ chave e a porta é possível reconhecer um narrador em terceira pessoa, porém a oscilação de seu foco nos permite observar a história de ângulos distintos. Nesse último, a alternância entre as conjugações verbais "falávamos", "falavam" e "falava", na passagem do primeiro ao segundo parágrafo, já indica a estreita zona de contágio sobre a qual se constrói o texto, no qual o discurso do narrador se funde com o do protagonista através do uso do discurso indireto livre, marcado, por sua vez, pela presença do outro personagem, que vem somar-se ao encontro.

Em outros casos, são as marcações tipográficas que assinalam a presença de outra perspectiva no discurso, e quando isso ocorre, não é apenas o sujeito que se mostra rachado pelo contato; é também a visão do texto que se expande, na revelação de novos estados perceptivos. Em $O$ afogado, por exemplo, o discurso do narrador em terceira pessoa é invadido por fragmentos em itálico, que atravessam o seu enunciado, dirigindo-se ao protagonista, como uma espécie de aviso sobre as modificações que se põem em curso. Tais avisos se formulam como percepções que emergem do contato do protagonista com um desconhecido encontrado inconsciente na praia, visto que "[...] ele era a possibilidade negada de ampliar a visão" (ABREU, 2001, p. 87). Por isso, quando a voz do "estranho" se enuncia, é posta em uma coluna paralela à outra, cuja voz pertence ao protagonista, indicando ser na permutação entre ambos que reside o movimento da trama enunciada e a vidência que dela se eleva.

Já em Meio silêncio, tal modificação no tipo de letra serve, à primeira vista, unicamente para dar passagem à perspectiva intimista dos dois protagonistas. Porém, com essa diferença na tipografia, o narrador também enfatiza que a fronteira de contágio entre ambos é maior do que eles percebem, posto que o não dito explicitamente, conforme sugere o título, aparece lá, no fluxo de consciência de 
ambos que, sim, se move continuamente em direção ao outro, mesmo que eles não saibam que, conforme nota o narrador, "[...] um vento mais frio os faz encolheremse juntos, unidos no mesmo abraço, na mesma espera desfeita, no mesmo medo. Na mesma margem" (ABREU, 2005a, p. 87).

Essa abertura em relação ao outro ocorre porque a focalização nos textos de Caio Fernando Abreu não costuma formular-se de uma posição distanciada, objetiva; ao contrário, ela se vê interligada com a subjetividade e seus processos. Por isso, e conforme afirma Bruno de Souza Leal, quando os textos são narrados em terceira pessoa, "[...] o narrador não acena com julgamentos morais radicais, com condenações inapeláveis. Ele é, sempre, em última instância, solidário" (LEAL, 2002, p. 60).

Esse aspecto pode ser observado mais pontualmente no conto intitulado $O$ rapaz mais triste do mundo, pois embora o narrador situe a sua perspectiva de uma posição afastada, ao observar o movimento dos personagens se vê arrastado com eles em um devir mutante, ao qual também convida o leitor: "[...] somos três e um. 0 que vê de fora, o que vê de longe, o que vê muito cedo. Este, antevisão. Os três, o mesmo susto. Vendo de dentro emaranhados. Agora, quatro?" (ABREU, 2005b, p. 58). Nesse sentido, percebemos que aquele que narra, não tenta aprisionar o outro em contornos bem delimitados, mas busca lançá-los num movimento de experimentação, apostando na possibilidade de que do encontro surja algo novo.

No referido conto, o narrador, ao valer-se da metalinguagem, assumindo-se como aquele que cria, ilumina ser (o autor) um gesto, no gesto de jogar os dados: escolhendo o tom do encontro enunciado através das músicas escolhidas por ele e selecionando cenas a partir da posição em que as enquadra. De sua perspectiva, que ao longo do conto faz alusão à linguagem cinematográfica ${ }^{1}$ e vale-se de recursos fílmicos como a sonorização de imagens, os movimentos de câmera e o procedimento de montagem, ele enquadra o acontecimento narrado. Aqui, dois homens solitários num bar qualquer navegam em direção um ao outro e em direção a ele que os suga com seus "[...] olhos ávidos dos encontros alheios, para dar-lhes vida, mesmo esta precária, de papel, onde Zeus Olimpo Oxalá Tupã também exercem seu poder sobre predestinados simulacros" (ABREU, 2005b, p. 57).

Entretanto, a partir do momento em que são observados, estes anônimos que passariam despercebidos no bar abarrotado de gentes, fazem correr na tessitura do texto linhas de vida que escapam às deduções, que deslizam acontecendo pela ótica do narrador sem que ele possa controlá-las, incitando-o a mergulhar nas possibilidades do encontro ao qual ele dá passagem, mas que ao mesmo tempo o toma em seu movimento: "[...] eu invento, sou Senhor de meu invento absurdo e estupidamente real, porque o vou vivendo nas veias agora, enquanto invento" (ABREU, 2005b, p. 58). Logo, a perspectiva distanciada daquele que cria se rompe: estilhaçada e multiplicada nos comentários metaficcionais, que situam o narrador não apenas como o observador, mas também como um personagem, cuja percepção se modifica conforme a trama de seu enunciado avança.

\footnotetext{
1 "O rapaz mais triste do mundo" é, entre os contos do escritor gaúcho, um dos melhores exemplos do matiz fílmico de seus escritos, nos quais "[...] o cinema (ou uma ideia de cinema) aparece associado em Caio Fernando Abreu à prática da narrativa ou até a própria possibilidade de abordar a narrativa. A leitura literária de seus contos permite aos leitores a sensação de uma escritura feita para moldura ou tela de um filme" (ARAUJO, 2008, p. 36).
} 
Com suas descrições, percebemos que os personagens se encaixam em estereótipos, podem ser rostificados: um "[...] homem de quase quarentas anos, começando a beber um pouco demais, não muito, só o suficiente para acender a emoção cansada, e a perder cabelo no alto da cabeça, não muito, mas o suficiente para algumas piadas patéticas [...]" (ABREU, 2005b, p. 55) e um

rapaz de quase vinte anos, bebendo um pouco demais, não muito, como costumam beber esses rapazes de quase vinte anos que ainda desconhecem os limites e os perigos do jogo, com algumas espinhas, não muitas, sobras de adolescência espalhadas pelo rosto muito branco, entre fios dispersos de barba que ainda não encontrou aquela justa forma definitiva já arquitetada na cara dos homens de quase quarenta anos, como esse que está à frente dele (ABREU, 2005b, p. 56-57).

Além disso, ambos são descritos como sujeitos noturnos e pós-modernos: "[...] navegam entre punks, mendigos, neons, prostitutas e gemidos de sintetizador eletrônico" (ABREU, 2005b, p. 55); e agem de acordo com o contexto no qual estão imersos, encarnando atitudes projetadas e recorrentes: se vestem de escuro, "[...] como mandam os tempos, para não serem rejeitados [...]" (ABREU, 2005b, p. 58), bebem e fumam "[...] cigarros igualmente amassados, viciosos cigarros tristes desses que só homens solitários e noturnos rebuscam nas madrugadas pelo fundo dos bolsos dos casacos, tenham eles vinte ou quarenta anos [...]" (ABREU, 2005b, p. 58). No entanto, embora possam ser enquadrados em imagens comuns nesse ambiente, não se restringem a elas, sendo por isso que o narrador parece inseguro em relação às descrições que dá dos dois, afirmando que "[...]todas essas coisas um tanto vagas, um tanto tolas, são tudo o que posso dizer sobre ele [...]" (ABREU, 2005b, p. 55-56 e p.57), sobre eles: a frase é repetida na caracterização dos dois.

É que a trama, que parece estar sendo narrada no momento em que acontece, está aberta a possíveis imprevistos, e o narrador não está certo sobre o que pode suceder; ele é apenas um gesto, iluminado no ato de jogar as fichas na máquina de música ao lado da qual está sentado, e de onde, como afirma, se põe "[...] a criar claridades impossíveis e a ninar com canções malditas esse encontro inesperado, tanto por eles, que navegam cegos, quanto por mim, pescador sem anzol debruçado sobre a água do espaço que me separa deles" (ABREU, 2005b, p. 56). Logo, os personagens movimentam-se de acordo com os encontros produzidos e agem por si mesmos, escapando daquele que narra: "[...] não se olham [diz o narrador]. E não sou eu quem decide, são eles" (ABREU, 2005b, p. 58).

Como o espaço no qual estão imersos é configurado de forma a manter a distância e a indiferença nas relações inter-humanas, impedindo o estabelecimento de um contato mais cúmplice com o outro, há uma espécie de surpresa, por parte do narrador, quando o rapaz e o homem se olham, aceitando-se sem exigências e escapando da regra de conduta dominante, conforme sugere: "[...] sem que eu esteja prevenido, embora estivesse, porque fui eu quem armou essa cilada, de repente eles se olham bem dentro e fundo dos olhos um do outro" (ABREU, 2005b, p. 59). Assim, 
o que nasce desse contato é algo novo, inédito, um afecto inclassificável, que ele nem se atreve a nomear:

eles armam palavras que chegam até mim em fragmentos partidos pelo ar que nos separa, em forma de interrogações mansas, hesitantes, perguntas que cercam com cautela e encantamento um reconhecimento que deixou de ser noturno para transformar-se em qualquer outra coisa a que ainda não dei o nome, e não sei se darei, tão luminosa que parece cegar a mim também. Contenho o verbo, enquanto agora eles veem o que mal começa a se delinear, e eu acho belo (ABREU, 2005b, p. 59).

Enquanto visionário esse narrador vê e ouve uma possibilidade outra, e, por isso, corre atrás dessa linha de fuga para deixá-la passar, não no intuito de reterritorializá-la, mas de fazê-la crescer na desterritorialização, de maneira que permaneça aberta, não capturada. Por isso, para dizer esse encontro, que repercute na aceitação do outro em sua nudez, no contato sem solicitações, se torna crucial fazer a língua vibrar, forçá-la a dizer o indizível, esse afecto sem nome, que só nos alcança informe, ainda por emergir, e através de traços na escrita de linhas de picturalidade, como podemos ver nesta passagem: "De onde estou, vejo a alma dos dois brilhar. Amarelinho, violeta claro: dança sobre o lixo. Eles choram enquanto se acariciam. Um homem de quase quarenta anos e um rapaz de menos de vinte, sem idade os dois" (ABREU, 2005b, p. 62). Ou através de um devir música da escrita, capaz de fazer soar tanto o grito quanto a repercussão rascante que ele abre: “[...] as quatro mãos se apertam, se aquecem, se misturam, se confortam. Não negro monstro marinho viscoso. Mas sim branca estrela do mar. Pentáculo. Madrepérola. Ostra entreaberta exigindo a negra pérola arrancada da noite e da doença, puro blues" (ABREU, 2005b, p. 61).

E principalmente de um devir outro, pois é disso que se trata todo o texto. 0 possível, aberto pelo contato entre os dois personagens, que mesmo frente ao improvável "[...] se reconhecem, finalmente [...] aceitam se reconhecer" (ABREU, 2005b, p. 59), não se restringe a eles, mas se estende àquele que inventa: “[...] esse estranho poder demiúrgico me deixa ainda mais tonto que eles, quando levantam e se abraçam demoradamente à porta do bar, depois de pagarem a conta. Amantes, parentes, iguais: estranhos" (ABREU, 2005b, p. 62). E mais do que isso, também se volta ao âmbito da recepção, à medida que estabelece uma zona de contiguidade, entre eles; entre o narrador e eles; entre eles, o narrador e nós - leitores reclamados na figura do narratário:

Eu sou os dois, eu sou os três, eu sou nós quatro. Esses dois que se encontram, esse três que espia e conta, esse quatro que escuta. Nós somos um - esse que procura sem encontrar e, quando encontra, não costuma suportar o encontro que desmente sua própria sina (ABREU, 2005b, p. 62). 
Pelo menos, este é o convite: olhar o outro, porque a vida “[...] pode ser medo e mel quando você se entrega e vê, mesmo de longe" (ABREU, 2005b, p. 63). No entanto, para alcançar essa percepção, esse estado do sensível, inédito, é preciso estar disponível, vulnerável ao outro; é necessário mergulhar junto e ver, como sugere o narrador, ao mencionar que: "[...] uma luz vítrea começa a varar a névoa da noite onde eles estão mergulhados junto comigo, com você, peixes míopes apertando os olhos para se verem de perto, em close, e conseguem" (ABREU, 2005b, p. 62).

Logo, por configurar aquele que narra não como uma consciência monista, mas como um ponto de vista movediço, fragmentado e plural, a literatura de Caio Fernando Abreu investe em uma reconfiguração do sensível, ao passo que desprende o discurso de uma posição fixa e bem delimitada para produzir na tessitura do texto uma forma de encontro divergente daquela que, regendo as relações no contexto urbano e caótico figurado nos seus textos, impedia a criação de contatos mais verdadeiros e amistosos com o outro. Portanto, ao mesmo tempo em que a opção por um ângulo narrativo móvel racha a lógica dos estereótipos, ao revelar uma concepção de sujeito cambiante e fluídica, também compõe uma forma de ligação entre os sujeitos fictícios que se desentende com a postura artificial, indiferente e subjugadora, visível nos contatos interpessoais apresentados em grande parte de suas narrativas.

Essa desestabilização das normas relacionais e existenciais disponíveis ocorre porque é a partir da percepção de algo intolerável que o visionário vislumbra a eclosão de um novo campo de experiências. Logo, a visão potencializada nos referidos contos está relacionada com a possibilidade de engendrar uma mutação afetiva, iluminada, nesse caso, através da instabilidade acolhedora do foco narrativo. É que a amplitude de observação não é um assunto pessoal, mas se refere a um agenciamento coletivo de enunciação, à disponibilidade para perceber, a partir do desassossego, o debater-se de fluxos de desejo que exigem passagem; que sugerem, devido ao mal-estar ocasionado, a urgência em reconfigurar paisagens existenciais e relacionais que se mostram insuficientes. Por isso, a ativação de estados inéditos do sensível se vincula à experimentação enquanto poder de afetar e de ser afetado, enquanto disponibilidade para mover-se de seu lugar confortável e provar novas relações de forças, sem saber ao certo aonde essa dobra levará.

Disso resulta o não fechamento da visão na produção de uma mensagem. $\mathrm{Ou}$ seja, o que os visionários nos contos de Caio Fernando Abreu veem não é algo pronto, exato, mas uma possibilidade não efetuada, por vir, que lhes soa como urgência de mudança, experimentada num movimento contínuo de devir-outro. Em seus escritos, esses narradores se apresentam sempre abertos, incompletos, prestes a escapar de si mesmos e de suas convicções, trilhando o caminho sem saber aonde vai desaguar, despertando no fluxo, mas com os olhos embaçados, molhados da visão, de uma vida: líquida, corrente. Por conseguinte, o que eles descobrem, não é uma fórmula, uma verdade antes velada, mas um possível que só se afirma enquanto tentativa: na experimentação, a partir da qual eles entreveem um novo tom, uma nova vibração.

Na literatura caiofernandiana, a visão não é algo que se pronuncia, mas uma busca, uma experimentação, pois aquele que vê está sempre inseguro em relação ao 
que descobre, conforme notamos na impossibilidade de nomear a espécie de reconhecimento que se produz no encontro narrado em $O$ rapaz mais triste do mundo. Dita hesitação percorre toda a sua obra, como dificuldade em exprimir objetivamente o pressentimento. É algo enunciado pelo narrador de Os Dragões não conhecem o paraíso, quando pondera: "Então, que seja doce [...] Mas, se alguém me perguntasse o que deverá ser doce, talvez não saiba responder. Tudo é tão vago como se fosse nada" (ABREU, 2005b, p. 130). Também visível na imprecisão formulada em Depois de agosto, tanto no que diz respeito ao que o outro diz; como na percepção difusa do narrador, que nos revela:

\begin{abstract}
Mas havia algo - um matiz? - nessa voz desse outro que o fazia ter nostalgia boa de gargalhar rouco jogando conversa fora com outras pessoas de qualquer lado - que não havia lados, mas lagos, desconfiava vago - como desde antes daquele agosto desaprendera a fazer (ABREU, 2002, p. 228).
\end{abstract}

Com esses exemplos, entre outros que podem ser buscados na obra do escritor gaúcho, nota-se a "[...] necessidade de não ter o controle da língua, de ser um estrangeiro em sua própria língua, a fim de puxar a fala para si, e 'pôr no mundo algo incompreensível"' (DELEUZE; GUATTARI, 1997b, p. 48, grifo dos autores). Assim, percebe-se que não é o resultado o que importa, mas os meios para potencializar as visões. Ou seja, se esses visionários não sabem exatamente o que veem, mas se o que veem só surge de um movimento contínuo de experimentação, poderíamos afirmar que a visão nas obras se refere à própria modificação que elas engendram.

Conforme notamos, ao revelar uma subjetividade em processo, cambiante, e que, por isso mesmo, se abre ao outro, sem tentar aprisioná-lo, já que a outridade é também parte potencial de si mesmo, os referidos escritos traçam linhas de fuga que desestabilizam as relações (sufocantes) vigentes no âmbito de seus universos ficcionais, vislumbrando e viabilizando uma diferença nos contatos, antes não reconhecível. Logo, essa modificação se investe contra o modelo dogmático da recognição, pois o não fechamento da mensagem aposta no próprio movimento de experimentação observado, em detrimento da produção de uma certeza, de uma verdade. Desse modo, lança uma possibilidade ao futuro: forçando-nos igualmente a pensar este algo ainda não formulado e que se agita através do desentendimento entre as duas espécies de encontros figurados, aqueles que empobrecem a potência da vida, e aqueles, cujo olhar mais maleável, se faz via de acesso a uma modificação por vir.

\title{
Referências
}

ABREU, Caio Fernando. 0 ovo apunhalado. Porto Alegre: L\&PM, 2001.

ABREU, Caio Fernando. Ovelhas Negras. Porto Alegre: L\&PM, 2002. 
ABREU, Caio Fernando. Caio 3D: o essencial da década de 1970. Rio de Janeiro: Agir, 2005a.

ABREU, Caio Fernando. Caio 3D: o essencial da década de 1980. Rio de Janeiro: Agir, 2005b.

ARAUJO, Rodrigo da Costa. Matrizes fílmicas na narrativa pós-moderna de Caio Fernando Abreu. Dissertação (Mestrado). Universidade Federal Fluminense, 2008. 108f.

DELEUZE, Gilles; GUATTARI, Félix. Mil platôs: capitalismo e esquizofrenia. Trad. de Aurélio Guerra Neto, Ana Lúcia de Oliveira, Lúcia Cláudia Leão e Suely Rolnik. São Paulo: Ed. 34, 1996. Vol. 3.

DELEUZE, Gilles; GUATTARI, Félix. Mil platôs: capitalismo e esquizofrenia. Trad. de Peter Pál Pelbrat e Janice Caiafa. São Paulo: Ed. 34, 1997b. Vol. 5.

LEAL, Bruno Souza. Caio Fernando Abreu, a metrópole e a paixão do estrangeiro: contos, identidade e sexualidade em trânsito. São Paulo: Annablume, 2002.

ROLNIK, Suely. Uma insólita viagem à subjetividade: fronteiras com a ética e a cultura. 1997. Disponível em:

http://www.pucsp.br/nucleodesubjetividade/Textos/SUELY/viagemsubjetic.pdf Acesso em: 22 de jun de 2020.

ROLNIK, Suely. Geopolítica da cafetinagem. 2006. Disponível em: http://www.pucsp.br/nucleodesubjetividade/Textos/SUELY/Geopolitica.pdf Acesso em jun 2012.

ROLNIK, Suely. Cartografia sentimental: transformações contemporâneas do desejo. Porto Alegre: Sulina, 2011.

ZOURABICHVILI, François. Deleuze e o possível (sobre o involuntarismo na política). In: ALLIEZ, Eric (org.) Gilles Deleuze: uma vida filosófica. Coordenação da tradução de Ana Lúcia de Oliveira. São Paulo: Ed. 34, 2000.

\section{Para citar este artigo}

FORSTER, G. Da vidência narrativa nos escritos de Caio Fernando Abreu. Macabéa - Revista Eletrônica do Netlli, Crato, v. 10, n. 4, 2021, p. 199-210.

A Autora

GABRIELLE FORSTER é doutora em Estudos Literários pela UFSM. Mestre em História da Literatura pela FURG. 